\title{
Control of Acidosis during Exchange Transfusion with Citrated Blood
}

\author{
GILLIAN GANDY, JAMES W. PARTRIDGE, and DOUGLAS GAIRDNER \\ From the Cambridge Maternity Hospital
}

In a previous paper (Calladine et al., 1965) it was shown that during exchange transfusion with citrated blood an acidosis often developed in babies transfused on the first day of life, but not in those transfused on the third day or later. The acidosis in the babies concerned was sometimes severe, and was occasionally associated with clinical symptoms. It was concluded that in performing exchange transfusion on the first day of life, it would be logical to offset the tendency to acidosis, for instance, by adding sodium bicarbonate to the donor blood. Barrie (1965) has since described this approach; our own results reported here have led to conclusions that differ only in a quantitative respect from his.

\section{Material and Methods}

A total of 22 babies was studied: all had Rh haemolytic disease of moderate to severe degree, and were Coombs positive. Gestation periods varied from 36 to 40 weeks, birthweights from 2.0 to $3.75 \mathrm{~kg}$., cord blood $\mathrm{Hb}$ from $4.6 \mathrm{~g}$. to $17.2 \mathrm{~g} . / 100 \mathrm{ml}$., and cord plasma bilirubin from 0.9 to $7.1 \mathrm{mg} . / 100 \mathrm{ml}$.

Exchange transfusion was begun from 3/4 to 20 hours after birth. In 18 infants it was carried out by a continuous method utilizing both umbilical artery and vein (Gairdner, 1966), and in the remaining 4 by the conventional discontinuous method, $20 \mathrm{ml}$. aliquots being aspirated and injected via the umbilical vein. The volume of blood exchanged was $180 \mathrm{ml} / \mathrm{kg}$. in 2 hours. Acid-citrate-dextrose (ACD) blood less than 5 days old was used, its composition being as given previously (Calladine et al., 1965). From a $540 \mathrm{ml}$. bottle of blood about $150 \mathrm{ml}$. supernatant plasma was removed; $5 \%$ $\mathrm{NaHCO}_{3}$ was then added in varying amounts to one or both of two bottles, one of which provided blood for the first hour of the transfusion and one for the second hour.

The standard bicarbonate of ACD blood (moderately concentrated) was about $4 \mathrm{mEq} / \mathrm{l}$. The addition of 10 , 20 , and $25 \mathrm{mEq} \mathrm{NaHCO}$ per litre of blood was found to raise its standard bicarbonate to about 10,14, and $20 \mathrm{mEq} / \mathrm{l}$., respectively.

Blood samples were taken from infants (1) before

Received July 18, 1967. transfusion, (2) after 1 hour, at mid-transfusion, and (3) after 2 hours, at end-transfusion. In 18 cases samples were arterial from the umbilical artery catheter, and in 4 from the umbilical vein catheter, and were analysed by the Astrup technique for $p \mathrm{H}, \mathrm{PCO}_{2}$, and standard bicarbonate. (Standard bicarbonate values, which were our main concern, are the same whether arterial or venous blood is sampled (Gandy et al., 1964).) In some cases blood was also sampled on the day after transfusion, using heel-prick.

\section{Results}

Changes in the acid-base state of each infant during the course of transfusion are presented in terms of standard bicarbonate values. $\mathrm{PCO}_{2}$ values remained near normal (below $48 \mathrm{~mm} . \mathrm{Hg}$ ) in all except 5 infants, in whom values up to $58 \mathrm{~mm} . \mathrm{Hg}$ occurred. $p \mathrm{H}$ therefore tended to run parallel to changes in standard bicarbonate. In no case did $p \mathrm{H}$ fall below $7 \cdot 1$.

In the first series of 7 infants the amount of $\mathrm{NaHCO}_{3}$ added to the donor blood varied from 1.2 to $3.0 \mathrm{mEq} / 100 \mathrm{ml}$. blood given in the first hour of the transfusion, and from 0 to $2.4 \mathrm{mEq} / 100 \mathrm{ml}$. blood given in the second hour of the transfusion. Results are shown in Fig. a. In the 3 infants in whom $\mathrm{NaHCO}_{3} 1.8$ or $2.4 \mathrm{mEq} / 100 \mathrm{ml}$. was added to the second donor bottle, a slight alkalosis was produced by the end of the transfusion, the standard bicarbonate levels having risen to $27-28.5 \mathrm{mEq} / 1$.

In the second series of 7 infants, therefore, the amount of $\mathrm{NaHCO}_{3}$ added to the first donor bottle was $1.8 \mathrm{mEq} / 100 \mathrm{ml}$., but none was added to the second bottle. Results (Fig. b) show that while this dosage scheme gave a satisfactory control of acidosis over the first half of the procedure, it failed in most cases to prevent acidosis from developing during the second half, 2 of the 7 showing a large fall in standard bicarbonate to 13 $\mathrm{mEq} / \mathrm{l}$. or below.

Finally, in the third series of 8 infants, the amount of $\mathrm{NaHCO}_{3}$ added to the first bottle was as in the previous series, $1.8 \mathrm{mEq} / 100 \mathrm{ml}$, and in 

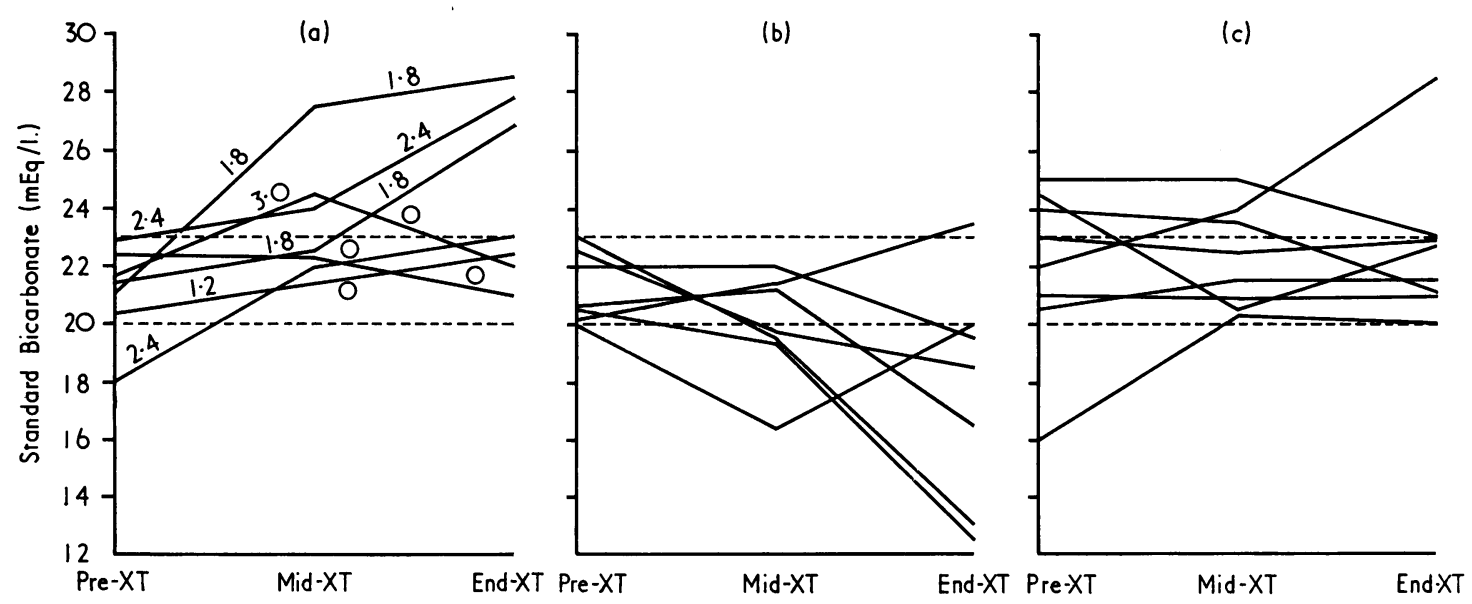

FIG.-Standard bicarbonate during exchange transfusion with the addition of varying amounts of sodium bicarbonate to blood transferred in the first and second half of procedure. Broken lines indicate normal range of standard bicarbonate. (a) 7 infants: sodium bicarbonate added to donor blood in amounts of 1.2 to $3.0 \mathrm{mEq} / 100 \mathrm{ml}$. in first half of transfusion, and of $0,1 \cdot 8$, or $2 \cdot 4 \mathrm{mEq} / 100 \mathrm{ml}$. in second half of transfusion. (b) 7 infants: sodium bicarbonate $1 \cdot 8 \mathrm{mEq} / 100 \mathrm{ml}$. added to donor blood in first half of transfusion only. (c) 8 infants: sodium bicarbonate $1.8 \mathrm{mEq} / 100 \mathrm{ml}$. added to donor blood in first half, and $0.9 \mathrm{mEq} / 100 \mathrm{ml}$. added to donor blood in second half of transfusion.

addition half this amount, $0.9 \mathrm{mEq} / 100 \mathrm{ml}$., was added to the second bottle. Results (Fig. c) show that this scheme provided a satisfactory control of the acid-base state of the baby throughout the 2-hour transfusion in all the infants, except that one showed a slight alkalosis, the standard bicarbonate rising to $28 \cdot 5 \mathrm{mEq} / \mathrm{l}$. by the end of transfusion.

In the previous study we drew attention to the alkalosis that develops during the day after exchange transfusion, as the citrate anticoagulant is metabolized. Since the addition of $\mathrm{NaHCO}_{3}$ to the transfused blood might augment this post-transfusional alkalosis, we measured the standard bicarbonate in 14 babies at between 12 and 36 hours after transfusion. The highest value recorded was in one in the second series in whom standard bicarbonate rose to $39.5 \mathrm{mEq} / \mathrm{l}$. at 21 hours after

\section{TABLE}

Amount of Sodium Bicarbonate to be Added to ACD Blood (per $100 \mathrm{ml}$. moderately concentrated blood)

\begin{tabular}{|c|c|c|}
\hline Amount $\mathrm{NaHCO}_{3}$ & $\begin{array}{c}\text { First Bottle } \\
\text { Donor Blood }\end{array}$ & $\begin{array}{l}\text { Second Bottle } \\
\text { Donor Blood }\end{array}$ \\
\hline 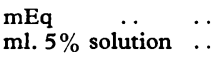 & $\begin{array}{l}1 \cdot 8 \\
3 \cdot 0\end{array}$ & $\begin{array}{l}0.9 \\
1.5\end{array}$ \\
\hline
\end{tabular}

transfusion, though without any accompanying clinical symptoms. In the remaining 13 infants standard bicarbonate ranged from 25 to $33 \mathrm{mEq} / \mathrm{l}$.

\section{Discussion}

Our results led to the conclusion that the most appropriate amount of $\mathrm{NaHCO}_{3}$ to be added to ACD blood in order to maintain a normal acid-base situation during exchange transfusion was that used in the third series. The amount is set out in the Table, and is applicable to infants transfused on day 1 , who are of more than 36 weeks' gestation, and whose acid-base state before transfusion is not grossly abnormal.

The amounts quoted apply to exchange transfusion using moderately concentrated ACD blood, and where $180 \mathrm{ml} . / \mathrm{kg}$. is exchanged in a period of 2 hours. This scheme probably differs little from that current in most centres, so that it is hoped that the amounts quoted here may be applicable generally.

Barrie (1965) titrated ACD blood with $\mathrm{NaHCO}_{3}$ to bring its base deficit down to about $10 \mathrm{mEq} / 1$., and found that this required the addition of $1.2 \mathrm{mEq}$ $\mathrm{NaHCO}_{3} / 100 \mathrm{ml}$. blood, if ACD blood was fresh and not packed; and $2.5 \mathrm{mEq} / 100 \mathrm{ml}$. blood when ACD blood was 1-3 days old, and moderately 
packed. Exchange transfusion on 3 babies on the first day of life, using donor blood so treated, was accompanied by a satisfactory control of acid-base values (Barrie, 1965). The amount of $\mathrm{NaHCO}_{3}$ to be added to moderately concentrated blood 1-3 days old, as recommended by Barrie $-2.5 \mathrm{mEq} / 100 \mathrm{ml}$., is thus a good deal larger than we have found necessary (see Table). MacRae and Palavradji (1965) injected via the umbilical vein $1 \mathrm{mEq} \mathrm{NaHCO}$ with every $100 \mathrm{ml}$. blood given during exchange transfusion; their dosage scheme was, therefore, fairly similar to ours, and in 3 cases recorded gave satisfactory control of acidosis.

Varga and Hutás (1966) monitored acid-base values in a series of infants during exchange transfusion, and concluded that the addition of alkali was unnecessary, but only 1 of their 12 was transfused on the first day of life, at the time, that is, when acidosis is liable to develop during exchange transfusion (Calladine et al., 1965).

Alkalosis developing during the day following exchange transfusion was of slight degree in 13 of the 14 infants in our series in whom this point was studied, standard bicarbonate ranging from 25 to $33 \mathrm{mEq} / \mathrm{l}$. In the remaining infant it rose to a higher level of $39.5 \mathrm{mEq} / 1$., though surprisingly this baby was in the second series, i.e. no bicarbonate was added to the donor blood given in the second half of the transfusion. With this exception, our present range of figures for standard bicarbonate on the day after transfusion is similar to that recorded in our previous paper, $27-33 \mathrm{mEq} / \mathrm{l}$., for a comparable group of 5 infants in whom no sodium bicarbonate was added to donor blood. Thus, addition of sodium bicarbonate in the amounts used here did not augment the alkalosis which ordinarily occurs after exchange transfusion with citrated blood.

As the addition of sodium bicarbonate to donor blood is a simple matter, we suggest that it could with advantage be incorporated as a routine in all exchange transfusions with citrated blood carried out on the first day of life. It is not indicated as a routine in transfusions carried out after day 1 , because, as our earlier studies indicated, mature babies, at least, do not then show the same tendency to develop acidosis during exchange transfusion. There are insufficient facts to determine how premature babies more than 1 day old behave in this respect. The addition of bicarbonate or THAM (Oliver, 1965) to donor blood might, however, be indicated in an older infant if acidosis were present initially, as for instance as a result of pulmonary disorder.

Extremely sick infants require an individual approach. It may be wise to repair an initial severe acidosis before starting exchange transfusion. This was illustrated by the case of an infant with haemolytic disease (not included in the present series) who was delivered at 35 weeks' gestation with cord $\mathrm{Hb}$ only $2.7 \mathrm{~g} . / 100 \mathrm{ml}$. At 2 hours old, when exchange transfusion was begun, $p \mathrm{H}$ was 6.98 , standard bicarbonate $10.8 \mathrm{mEq} / \mathrm{l}$., and $\mathrm{P}_{\mathrm{a}} \mathrm{CO}_{2} 53 \mathrm{~mm}$. $\mathrm{Hg}$. More than the usual amounts of $\mathrm{NaHCO}_{3}$ were added to the donor blood $(2 \cdot 7 \mathrm{mEq}$ and $1 \cdot 8$ $\mathrm{mEq} / 100 \mathrm{ml}$. for the first and second hours of the transfusion, respectively), but this proved inadequate to repair the severe acidosis which still persisted by the end of the transfusion when $p \mathrm{H}$ was 7.08 , standard bicarbonate was $13.5 \mathrm{mEq} / \mathrm{l}$, and $\mathrm{P}_{\mathrm{a}} \mathrm{CO}_{2}$ was $51 \mathrm{~mm} . \mathrm{Hg}$. Failure to deal early with the acidosis may have contributed to this infant's death at 36 hours from respiratory failure.

In any large series of exchange transfusions there will usually be some infants who show a sudden deterioration during the procedure, and an occasional inexplicable fatality (Van Praagh, 1961). In our previous paper (Calladine et al., 1965) we gave an account of one such episode, and were able to document the fact that clinical deterioration coincided with the development of a marked acidosis. Prevention of acidosis might well contribute to a reduction in mortality from exchange transfusion.

\section{Summary and Conclusions}

Acidosis, sometimes of severe degree, may develop during exchange transfusion with citrated blood in infants transfused on the first day of life. In studies on 22 infants it was shown that, by adding sodium bicarbonate to the donor blood, such acidosis could be prevented.

It is suggested that sodium bicarbonate 1.8 $\mathrm{mEq} / 100 \mathrm{ml}$. should be routinely added to the donor blood given in the first half of an exchange transfusion, and half that amount $(0.9 \mathrm{mEq} / 100 \mathrm{ml}$.) to the blood given in the second half. Using this scheme, post-transfusional alkalosis was not augmented.

Infants who are very premature, very sick, or very acidotic require a more individual approach.

This work was supported by a grant from the Medical Research Council.

\section{REFERENCES}

Barrie, H. (1965). Acid-base control during exchange transfusion. Lancet, 2, 712.

Calladine, M., Gairdner, D., Naidoo, B. T., and Orrell, D. H. (1965). Acid-base changes following exchange transfusion with citrated blood. Arch. Dis. Childh., 40, 626. 
Gairdner, D. (1966). Exchange-transfusion techniques. Lancet, $2,545$.

Gandy, G., Grann, L., Cunningham, N., Adamsons, K., Jr., and James, L. S. (1964). The validity of $p \mathrm{H}$ and $\mathrm{PCO}_{2}$ measurements in capillary samples in sick and healthy newborn infants. Pediatrics, 34, 192.

MacRae, D. J., and Palavradji, D. (1965). Acid-base balance in exchange transfusion. $\mathcal{F}$. Obstet. Gynaec. Brit. Cwlth, 72, 384.
O'iver, T. K., Jr. (1965). The use of THAM-buffered ACD blood in high risk infants who require exchange transfusion (abstr.). F. Pediat., 67, 951.

Van Praagh, R. (1961). Causes of death in infants with hemolytic disease of the newborn (erythroblastosis fetalis). Pediatrics, 28, 223.

Varga, F., and Hutás, S. (1966). Alterations in blood $p \mathrm{H}$ and acidbase parameters during exchange transfusion in the newborn. Biol. Neonat. (Basel), 10, 55. 